\title{
Impact Of HIV in Livelihood -A Review
}

\author{
Sivakumar. $\mathrm{T}^{1^{*}}$, Vinoth $\mathrm{K}^{2}$, Chellapan $\mathrm{N}^{3}$, Vasanthi. $\mathrm{R}^{4}$ \\ ${ }^{1}$ Professor, Department of Pharmaceutical Chemistry, Nandha College of Pharmacy, \\ Erode, Tamilnadu, Email: sivancp2021@yahoo.co.in \\ ${ }^{2}$ Associate Professor, Department of Pharmaceutics, Nandha College of Pharmacy, \\ Erode, Tamilnadu, Email: vinoth@nandhapharmacy.org \\ ${ }^{3}$ Assistant Professor, Department of Pharmaceutics, Nandha College of Pharmacy, \\ Erode, Tamilnadu, Email: Chellapan@nandhapharmacy.org \\ ${ }^{4}$ Professor, Department of Child Health Nursing, Nandha College of Nursing, Erode, \\ Tamilnadu, Email: rvasanthincn@gmail.com \\ ${ }^{*}$ Corresponding Author
}

\begin{abstract}
Livelihood approaches are getting paradigmatic in the discussion about provincial turn of events and neediness as they put individuals at the middle and take the issues and needs of individuals as a beginning stage for investigation and arranging. In Livelihood point of view to improvement doesn't supplant other country advancement draws near but instead expands on them. In this exploration a professional viewpoint was embraced to see how AIDS in a specific setting impacts the variety of occupation procedures that family units seek after to guarantee pay and food security and what blend of resources and assets families attract on to react to these effects
\end{abstract}

Keywords: Livelihood, HIV, Families

\section{Introduction}

The idea of livelihood has been broadly talked about, bringing about a scope of various definitions. As a rule, these definitions show that livelihood is about the available resources individuals earn enough to pay the rent just as the assets individuals have and how they utilize these. These resources can be unmistakable, for example, domesticated animals and stores, and elusive, for example, claims and access. An livelihood is viewed as manageable when it can adapt to and recuperate from stresses and stuns and keep up or improve its abilities and resources both now and later on, while not sabotaging the normal asset base. a occupational contains the exercises, the resources, and the admittance to these that mutually decide the living picked up by an individual or family. Occupation age includes all exercises individuals embrace to meet their essential necessities and the term livelihood is utilized for the result of those exercises. The livelihood framework includes inputs, which they call assets and resources, and throughputs, which involve the handling, use and the board of the sources of info, which together produce an ideal yield or business. An occupation structure depends on the suspicion that individuals work in a specific weakness setting, which is characterized by for instance climatic varieties, momentary financial stuns and longer-term patterns. Inside this specific situation, individuals draw on a blend of occupation resources or capitals (human, social, monetary, physical and regular) to seek after an assortment of business systems that would bring about a scope of livelihood results, which are pretty much quantifiable, for example, food security, pay, wellbeing, prosperity and decreased weakness. Nonetheless, admittance to resources and livelihood methodologies and the manner in which resources and work exercises are changed over into livelihood results are additionally much impacted by the weakness setting and by the predominant institutional and hierarchical climate.

\section{Central to the Livelihood Framework}

A few kinds of assets can be recognized, including HR, for example, abilities and work, material assets, for example, land, family water supply, animals, ranch and gainful gear and pay, and ecological assets, for example, water and trees, yet in addition establishments, connection organizations and formal and casual associations. Family units are believed to develop their job procedures by drawing on human resources, social connection, monetary capital, actual capital and characteristic capital. To make livelihood, family units should consolidate their distinctive capital gifts. This hence requires a disaggregated examination of jobs, which takes a gander at people or gatherings of social entertainers comparable to access and command over resources and assets. One of the fundamental considerations of the vocation approach is that it tries to accomplish different work results, to be controlled by individuals 
themselves, which infers that business age isn't just a matter of pay or material accomplishments. This implies that livelihood ought to be viewed as a dynamic and all-encompassing idea, which incorporates both material and nonmaterial parts of prosperity. Resources are not just assets that individuals use in building jobs: they are resources that give them the capacity to be and to act. Resources ought not to be seen distinctly as things that permit endurance, variation and neediness annihilation: they are likewise the premise of specialists' capacity to act and to recreate, challenge or change the guidelines that administer the control, use and change of assets. Culture is a significant factor that impacts families' occupation methodologies and their capacities to adapt to stuns. All things considered, culture decides one's conduct, characterizes what freak conduct is, and how in the end this conduct can break or make the structures that keep individuals poor.

\section{Social Connections}

The idea of social assets isn't new and has been concentrated broadly in the past under different names. Despite the fact that social assets is presently broadly utilized in writing, writers vary in their considering social assets and there exist a large number of meanings of the idea. Social assets is essential for individuals' family connections, especially between generationally, which assists with expanding human resources, which thus results into financial returns. Social assets is comprised of the two organizations of inscriptive and elective connections between people, which might be vertical as in power connections, or even as in deliberate associations, and of the trust and assumptions which stream inside those organizations. It centers on the relations an entertainer keeps up with different entertainers. Social capital is viewed as an asset that encourages activities of people and gatherings by excellence of their immediate and circuitous connects to different elements in interpersonal organizations. Social assets brings about fortitude. Solid normal practices and convictions, which are regularly found in shut informal organizations, cause people to agree to the set up guidelines and customs and thus diminish the requirement for formal checks. Social assets additionally assists people and family units in adapting to vulnerabilities, chronic sickness, food shortfalls, monetary requirements and different burdens.

Informal communities can reject outcasts as the very solid ties that yield advantages to amass individuals can keep others from access. Likewise, an abundance of cases on gathering individuals can forestall the accomplishment of the gathering undertaking or that of the individual individuals. At last, solid authorization of nearby standards will in general confine singular opportunity and independence

\section{Economic capital}

Monetary capital incorporates money, reserve funds, advances or credit and other financial resources accessible to family units and is a vital contribution for seeking after an occupation. The transformation of their creation into money, and formal and casual getting. HIV/AIDS puts an extreme strain on families' monetary capital through high hospital expenses, memorial service costs and related vehicle costs. Additionally, HIV/AIDS impacts monetary capital through decreased pay from on and off-ranch sources because of ailment and demise. In numerous social orders, ladies are generally allocated a supporting job meaning they are answerable for thinking about the wiped out just as for the homegrown and food creation exercises of the family. Wholesome deficiency likewise impacts individuals' working limit as it decreases individuals' solidarity and energy to do actual work. HIV/AIDS negatively affects individuals' dietary status and subsequently their profitability through an expansion in resting energy consumption, a decrease in individuals' food admission, supplement mal retention and misfortune, and complex metabolic modifications that bring about weight reduction and squandering. Common capital involves the regular assets, for example, land, water, organic assets, woods and field regions based on which families determine their job. This characteristic asset base gives families the methods for creation, pay age, utilization, prescriptions, sanctuary and energy supply. To save or improve the common asset base for the present and people in the future is a significant part of economical vocations. Business exercises are viewed as unreasonable when they harm the characteristic asset base by adding to desertification, deforestation, soil disintegration, salinization, etc.

Destitute individuals should adjust contending needs for safeguarding their resources, producing pay and making sure about present and future food supplies. As an outcome people may choose to go hungry up somewhat to meet another level headed as was found during the mid-80s starvation in Sudan, where individuals decided to go hungry to safeguard their resources and subsequently their future occupations. On the succession of conduct reactions family units utilize in the midst of stress, families in a few African and Asian nations needs resource conservation above guaranteeing prompt food needs until they arrive at a state of dejection.

\section{Livelihood Approach}

Work techniques incorporate the various exercises families attempt based on the various resources they approach to produce a business. They may involve a scope of exercises, including paid work and unpaid work, food and domesticated animals creation, amassing and ventures, acquiring, little endeavor advancement, person to person communication, network overseeing and participation,. In any case, the real circumstance can be with the end goal that 
families don't have a scope of alternatives to browse that grants long haul getting ready for the future yet need to make compromises to make due in the present. The term methodology further infers a dynamic cycle whereby the family, in a cognizant way, designs its activities. Nonetheless, truly the dynamic that underlies family vocation techniques is perplexing. The interests, needs and targets of a family, the assets accessible and the setting of a family all impact the choices on the exercises a family unit embraces to fulfill its requirements in the shortand long haul. Moreover, choices on occupation systems rely upon what advancement, destitution and business intend to individuals, the limitations under which family units settle on their choices and the force relations at play. Farming increase, for example an expansion of yield from a given measure of land through more work or capital speculations, versus farming strengthening, for example an expansion in land under development. Vocation expansion, which means families receive a scope of on-, migrant/or offranch exercises. Movement, for example family's individuals move away, incidentally or forever, looking for a work somewhere else. Family units pick up their job either from horticultural increase or escalation, expansion of a scope of exercises, movement, or most normally seek after a blend of these three methodology spaces, likewise called a 'business portfolio'. Some business portfolios can be profoundly focused on one or a restricted Gendered weakness to AIDS scope of exercises, while different portfolios might be extremely assorted. How much a family expands its work portfolio depends to an enormous degree on the asset enrichments accessible just as the measure of danger associated with elective choices. Approaches are typically detailed and executed at various government levels and impact family dynamic and their admittance to and command over vocation resources. For instance, arrangements planned explicitly to impact common asset use and to ensure the climate may restrict destitute individuals' admittance to assets they customarily rely upon for their occupations. The 'measures' a piece of this measurement is a connecting factor and contains the cycles of progress in arrangements and organizations. For instance, cycles could incorporate a move towards political and monetary decentralization, intended to improve the exhibition of offices that have the ability to emphatically impact job possibilities and decisions

\section{Vulnerability to Livelihood}

Individuals' abilities are framed by the resources they approach and the outside climate they live in, which impacts the nearby setting and establishes the outer side of weakness. The weakness setting varies from the arrangement, establishments and cycles measurement of the outside climate in that it involves patterns, stuns and irregularity that are ordinarily viewed as exogenous, while the approach, foundations and cycles measurement comprises of social and political angles that are endogenous to the standards and rules of a general public. At the end of the day, the weakness setting causes consequences for vocations over which individuals have practically no control, while arrangements, establishments and cycles are the aftereffect of legislative issues, dynamic and exchange measures, in which nearby networks can really or possibly lock in. In any case, HIV/AIDS is certainly not an exogenous factor that is totally outside the ability to control of, and random to, family work frameworks. HIV/AIDS is endogenous to family unit business frameworks that are shaped and affected by individuals at various levels. While the facts confirm that many, particularly ladies and youngsters, have almost no influence over their defenselessness to HIV contamination, the fundamental sex jobs, social standards and force deviations that decide this danger are endogenous to a general public. Modifying these standards and rules is conceivable however may take ages. In actuality, AIDS is neither totally endogenous nor exogenous. While social factors that lead to an expanded HIV danger can somewhat be treated as endogenous, numerous different variables that empower the transmission of HIV.

\section{Sustainability of a Livelihood}

The manageability of a livelihood relies upon the degree of stable resources and assets family units approach and power over and how these resources are used, kept up and upgraded in order to protect them. The capacity to adapt to and recuperate from stresses and stuns is key to the meaning of reasonable vocations. Security is another significant element of job supportability. Occupations are viewed as secure when family units have secure responsibility for, admittance to, resources, assets and pay producing exercises, including stores to counterbalance hazards, ease stuns, and meet possibilities. Supportability into ecological and social manageability. Ecological supportability alludes to whether occupation exercises can keep up and improve the regular asset base at various levels or whether it prompts natural debasement. Social maintainability centers on the human side and is worried about whether individuals or family units are capable not exclusively to pick up yet in addition to keep a satisfactory and good livelihood.

\section{Conclusion}

The system likewise assists with seeing how the large scale climate impacts individuals' jobs, make country families powerless against HIV/AIDS effects, and put them at more serious danger to HIV openness. Various factors, for example, the weakness setting and the common arrangement and institutional climate affect the family resource base and their decision of job technique and impact what assets various families can prepare to react to AIDS impacts. The advantage of an occupation structure is subsequently that it assists with understanding different elements that impact 
jobs and that may or probably won't associate with HIV/AIDS. These results incorporate such things as food security, pay, wellbeing, prosperity and diminished weakness.

\section{References}

1. Lewis. W.A (1954). "Economic Development with Unlimited supply of Labor", The Manchester School.

2. Maxwell D, Caldwell R. (2008) The Coping Strategy Index: Field Methods manual, second ed.

3. Barnett, T. and A. Whiteside (2001). 'The social and economic impact of HIV/AIDS in poor countries: a review of studies and lessons', Progress in Development Studies 1(2): 151- 170.

4. Barnett, T. and A. Whiteside (2002). AIDS in the Twenty-First Century: Disease and Globalization. New York: Palgrave Press.

5. United Nations (2005). Designing Household Survey Samples: Practical Guidelines Designing Household Survey Samples: Practical Guidelines. Studies in Methods Series F No.98

6. Whitehead, A. \& Tsikata, D. (2003): Policy discourses on women's land rights in subSaharan Africa: The Implications of the Re-turn to the Customary

7. Whitehead, A. (2002): Failing women, sustaining poverty: Gender in poverty reduction strategy papers.

8. Scoones, I., (1998): Sustainable Rural Livelihoods: A framework for analysis. IDS, Working Paper 72, IDS, Brighton, UK. June 1998.

9. Rakodi, Carole,( 2002): 'A Livelihoods Approach Conceptual Issues and Definitions', in C. Rakodi and S. Romaya (eds), 2002, Building Sustainable Urban Settlements. Approaches and Case Studies in the Developing World, Urban Management Series, London: ITDG Publishing.

10. Putnam, R. D. (1998): Foreword for volume on social capital, Housing Policy Debate. 9, v-vii Republic of Ghana Ministry of Lands and Forestry, National Land Policy 1 (1999) [hereinafter National Land Policy]. 